\title{
Contemporary Labor Patterns: The Impact of Maternal Body Mass Index
}

\author{
Michelle A. KOMINIAREK, MD ${ }^{1,2}$, Jun ZHANG, PhD, MD ${ }^{3}$, Paul VANVELDHUISEN, PhD $^{4}$, \\ James TROENDLE, PhD $^{3,5}$, Julie BEAVER, MS $^{3}$, and Judith U. HIBBARD, MD ${ }^{1}$ \\ ${ }^{1}$ Division of Maternal-Fetal Medicine, Department of Obstetrics and Gynecology, University of \\ Illinois at Chicago, Chicago, Illinois ${ }^{2}$ Division of Maternal-Fetal Medicine, Department of \\ Obstetrics and Gynecology, Indiana University School of Medicine, Indianapolis, Indiana ${ }^{3}$ Division \\ of Epidemiology, Statistics and Prevention Research, NICHD, NIH, Bethesda, Maryland ${ }^{4}$ The \\ EMMES Corporation, Rockville, Maryland ${ }^{5}$ Division of Cardiovascular Sciences, NHLBI, NIH, \\ Bethesda, Maryland
}

\begin{abstract}
Objective-To compare labor patterns by body mass index (BMI).

Study Design - 118,978 gravidas with a singleton term cephalic gestation were studied. Repeated-measures analysis constructed average labor curves by parity and BMI categories for those that reached $10 \mathrm{~cm}$. Interval censored regression analysis determined median traverse times adjusting for covariates in vaginal deliveries and intrapartum cesareans.

Results-For nulliparas, the time difference to reach $10 \mathrm{~cm}$ was 1.2 hours from the lowest to highest BMI category. Multiparas entered active phase by $6 \mathrm{~cm}$, but reaching this point took longer for $\mathrm{BMI} \geq 40.0$ (3.4hours) compared to $\mathrm{BMI}<25.0$ (2.4hours). Progression by centimeter $(\mathrm{P}<0.001)$ except from $7-9 \mathrm{~cm}$ in multiparas $(\mathrm{P}>0.05)$, and from $4-10 \mathrm{~cm}(\mathrm{P}<0.001)$ increased as $\mathrm{BMI}$ increased for nulliparas and multiparas. Second stage length with and without an epidural was similar among BMI categories for nulliparas $(\mathrm{P}>0.05)$, but decreased as BMI increased for multiparas $(\mathrm{P}<0.001)$.
\end{abstract}

Conclusion-Labor proceeds more slowly as BMI increases suggesting that labor management be tailored to allow for these differences.

\section{Keywords}

Body mass index; Labor curves; Obesity; Pregnancy

(C) 2011 Mosby, Inc. All rights reserved.

Corresponding Author: Michelle A. Kominiarek, MD, Department of Obstetrics and Gynecology, Division of Maternal-Fetal Medicine, 820 South Wood Street M/C 808, Chicago, Illinois 60612, (312) 413-4888 office, (312) 996-4238 fax, Mkomin1 @uic.edu. Presented as an oral at the Annual Meeting for the Society of Maternal Fetal Medicine in San Francisco, California on February 12, 2011.

Publisher's Disclaimer: This is a PDF file of an unedited manuscript that has been accepted for publication. As a service to our customers we are providing this early version of the manuscript. The manuscript will undergo copyediting, typesetting, and review of the resulting proof before it is published in its final citable form. Please note that during the production process errors may be discovered which could affect the content, and all legal disclaimers that apply to the journal pertain. 


\section{INTRODUCTION}

Cesarean deliveries (CD) have reached an all-time high in the United States - estimated at $32.9 \%$ in $2009 .{ }^{1}$ Explanations for these findings include delayed childbearing, more multiple gestations, fewer attempts at vaginal birth after $\mathrm{CD}$, and increasing maternal body mass. ${ }^{2,3}$ In parallel with this effect is the obesity epidemic. In 2007-2008, the prevalence of obesity among adults was $33.8 \%{ }^{4}$ There is a linear rise in $\mathrm{CD}$ as maternal body mass index (BMI) increases. 5,6 The explanation for this finding is unknown, but several theories have been proposed, including greater fetal size, soft tissue obstruction to labor, poor uterine contractility, more frequent inductions as a result of pregnancy complications, or care-giver biases. $^{6-11}$

The Friedman curve is a well-known figure to all clinicians who participate in the management of labor and delivery. However, the evaluation of labor progression is largely based on studies from the 1950's which described patients from a small homogeneous population. ${ }^{12,13}$ Subsequent studies have suggested that this curve may not apply to current obstetrical care. ${ }^{14-16}$ The Consortium on Safe Labor is a multi-centered retrospective study of electronic obstetrical databases whereby labor progression in patients with contemporary obstetrical characteristics (i.e. increasing maternal age and BMI) and practices (i.e. a greater proportion of patients with inductions and epidurals) was studied. The primary investigation from this database determined that cervical dilation progresses more slowly than previously described, especially at cervical dilations from 4 to $6 \mathrm{~cm} .{ }^{17} \mathrm{Few}$ studies have addressed the specific impact of BMI on labor progression. ${ }^{18-19}$ The purpose of the current study was to characterize labor progression in gravidas with respect to their BMI at labor admission. If differences in labor patterns based on maternal BMI are found, this may help optimize labor management and ultimately impact the $\mathrm{CD}$ rate.

\section{MATERIALS AND METHODS}

The Consortium on Safe Labor abstracted detailed labor and delivery information from deliveries occurring between 2002-2008 from electronic medical records in 12 clinical centers (with 19 hospitals) across 9 American College of Obstetricians and Gynecologists (ACOG) US districts. Detailed description of the study is provided elsewhere. ${ }^{17,20}$ Data on labor progression (repeated, time-stamped cervical dilation, station and effacement) were collected from the electronic labor database. Labor management protocols including the timing and frequency of cervical exams performed during labor varied across institutions. The Institutional Review Boards of all participating institutions approved the study.

There were a total of 228,668 deliveries (87\% of which occurred during 2005-2007) in the database. For the current study, deliveries were excluded based on the following criteria: unknown BMI on admission $(n=48,005)$; multiple gestation $(n=5,059)$; not term (outside gestational age of $37^{0 / 7}-41^{6 / 7}$ weeks; $\left.n=31,149\right)$; stillbirth $(n=2,046)$; breech fetal presentation $(\mathrm{n}=7,764)$, prior $\mathrm{CD}(\mathrm{n}=33,020)$; and no documented trial of labor (defined as at least two cervical examinations in the obstetrical database, $n=36,407$ ). The number of deliveries remaining, noting that some deliveries met more than one criterion, was 126,257. To avoid intra-person correlation, we selected the first delivery from each participant in the study, leaving 118,978 deliveries for analysis (Figure 1).

Women were then grouped into either nulliparas or multiparas. BMI categories were determined by World Health Organization criteria (normal $<25.0 \mathrm{~kg} / \mathrm{m}^{2}$, overweight 25.0 $29.9 \mathrm{~kg} / \mathrm{m}^{2}$, obese Class I $30.0-34.9 \mathrm{~kg} / \mathrm{m}^{2}$, obese Class II $35.0-39.9 \mathrm{~kg} / \mathrm{m}^{2}$, and obese Class III $\left.\geq 40 \mathrm{~kg} / \mathrm{m}^{2}\right) .{ }^{21}$ Other descriptive variables included maternal age, height, race, gestational age, diabetes (pregestational and gestational combined), cervical dilation and 
effacement at admission, augmentation, induction, operative vaginal delivery, epidural anesthesia, $\mathrm{CD}$, and birth weight. A cesarean for abnormal labor was one that was documented as "failure to progress" or "cephalopelvic disproportion" in the database. Pearson Chi-Square tests were used to compare the association between categorical variables and BMI category, and analysis of variance to statistically compare the association between continuous variables and BMI category.

A repeated-measures analysis with an $8^{\text {th }}$ degree polynomial model was used to construct average labor curves by parity using cervical dilation in centimeters $(\mathrm{cm})$ with PROC MIXED (SAS software version 9.2, Cary, N.C.). ${ }^{17,22}$ In this analysis, the starting point was set at the first time when the dilation reached $10 \mathrm{~cm}($ time $=0)$ and the time was calculated backwards (e.g. 60 minutes prior to complete dilation $=-60$ minutes). After the labor curve models had been computed, the x-axis (time) was reverted to a positive value (e.g. instead of -12 to 0 hours, it was transformed to 0 to 12 hours). The labor curves included only gravidas who reached $10 \mathrm{~cm}$. Because a large proportion of women were not admitted to labor and delivery until cervical dilation was $4 \mathrm{~cm}$ or greater, we started our labor curves at $4 \mathrm{~cm}$. SPLUS software version 6.1 was used to create the labor curve graphs.

To estimate duration of labor, we used interval censored regression to determine the distribution of times for progression from one centimeter of dilation to the next (called "traverse time") with the assumption that the labor data were log-normally distributed..$^{23,24}$ Although this analysis was also restricted to laboring gravidas, it included gravidas who ultimately had either a vaginal delivery or an intrapartum cesarean. The median and $95^{\text {th }}$ percentiles were calculated for the first stage of labor and the Chi-squared test was used to test the significance of the BMI groups. The median and $95^{\text {th }}$ percentiles for the second stage were derived from PROC UNIVARIATE (SAS software version 9.2, Cary, N.C). Tests of a continuous BMI covariate were used in GLM (SAS software version 9.2, Cary, N.C) to compare the trends in labor time as BMI increased. We compared the traverse times in the first stage of labor and the duration of the second stage, adjusting to the combined observed frequencies of maternal age, height, race, gestational age, diabetes, induction, augmentation, epidural [first stage only], operative vaginal delivery [second stage only], and birth weight using PROC LIFEREG (SAS software version 9.2, Cary, N.C.). Trends in the traverse times with BMI were obtained as tests of a continuous BMI covariate in the LIFEREG model. A P value $<0.05$ was considered statistically significant.

\section{RESULTS}

The characteristics of the population according to parity and BMI category are presented in Tables 1 and 2. The mean admission BMI was $30.5 \mathrm{~kg} / \mathrm{m}^{2}$ and $7.3 \%$ of gravidas had a BMI $\geq 40 \mathrm{~kg} / \mathrm{m}^{2}$. Nulliparas represented $48 \%$ of the population and $22 \%$ had a CD. As BMI increased, so did the occurrence of black race, diabetes, number of cervical exams, induction, $\mathrm{CD}$, and $\mathrm{CD}$ for labor abnormalities while the opposite was found for Caucasian race, admission cervical dilation and effacement, and operative vaginal delivery for all comparisons in nulliparas $(\mathrm{P}<0.001)$ and multiparas $(\mathrm{P}<0.05$ except for augmentation). As parity increased, so did maternal age, cervical dilation at admission, and diabetes but the opposite was found for gestational age, operative vaginal delivery, epidural use, and CD across all BMI categories.

Figure 2 shows the average labor curves for all nulliparas who eventually reached $10 \mathrm{~cm}$ dilation by each BMI category. For nulliparas, there was no apparent inflection point in any of the BMI labor curves and as such it was difficult to separate latent from active phase. The time difference to reach $10 \mathrm{~cm}$ was 1.2 hours from the lowest to highest BMI category. Similarly, by the time the BMI $<25 \mathrm{~kg} / \mathrm{m}^{2}$ category reached $10 \mathrm{~cm}$, the BMI $\geq 40 \mathrm{~kg} / \mathrm{m}^{2}$ 
category was only at $7.5 \mathrm{~cm}$. Figure 3 shows the average labor curves for all multiparas who eventually reached $10 \mathrm{~cm}$ dilation by each BMI category. For multiparas, there was an inflection point (denoting acceleration in labor) in the curve and most were in active phase by $6 \mathrm{~cm}$. However, as BMI increased, it took longer to reach $6 \mathrm{~cm}-2.4$ hours for BMI $<25$ $\mathrm{kg} / \mathrm{m}^{2}$ and 3.4 hours for BMI $\geq 40 \mathrm{~kg} / \mathrm{m}^{2}$. Furthermore, the time difference to reach $10 \mathrm{~cm}$ was approximately 1 hour from the lowest to the highest BMI category. Labor curves in spontaneous and induced labor for nulliparas and multiparas were also generated and the same result of slower labor progress with increasing BMI was seen (results not shown).

Tables 3 and 4 give the adjusted median traverse time with $95^{\text {th }}$ percentiles to progress from centimeter to centimeter, from 4 to $10 \mathrm{~cm}$, and the second stage duration with and without an epidural for nulliparas and multiparas, respectively. For nulliparas, the time to progress from centimeter to centimeter $(\mathrm{P}<0.001)$ and from 4 to $10 \mathrm{~cm}(\mathrm{P}<0.0001)$ increased with increasing BMI in both unadjusted (data not shown) and adjusted models. Similar observations were noted for multiparas in the time to progress from centimeter to centimeter $(\mathrm{P}<0.05)$ and from 4 to $10 \mathrm{~cm}(\mathrm{P}<0.0001)$, except in progressing from 7 to 8 and 8 to $9 \mathrm{~cm}$ where the length of time did not change significantly across BMI categories $(\mathrm{P}>0.05)$ in the adjusted model. There was no significant difference in the second stage length with and without epidural as BMI increased for nulliparas in the adjusted model ( $P>0.05$, Table 3). Second stage length decreased as BMI increased for multiparas with and without an epidural ( $\mathrm{P}<0.0001$, Table 4). Of note, the times to reach $10 \mathrm{~cm}$ differ among the labor curves (Figures 1 and 2) and the median traverse times (Tables 3 and 4) because the labor curves only included gravidas who reached $10 \mathrm{~cm}$ dilation whereas the traverse times also included those gravidas having intrapartum cesareans.

\section{COMMENT}

In this large multicenter study of contemporary labor practices across the United States, labor progressed more slowly with increasing admission BMI. These effects were significant for the first stage of labor in both nulliparas and multiparas and overall was more pronounced for nulliparas compared to multiparas as shown in the labor curves (time to reach $10 \mathrm{~cm}$, Figures 2 and 3) and the median traverse times to progress from 4 to $10 \mathrm{~cm}$ (i.e. 5.4 hours for BMI $<25 \mathrm{~kg} / \mathrm{m}^{2}$ compared to 7.7 hours for BMI $\geq 40 \mathrm{~kg} / \mathrm{m}^{2}$ in nulliparas vs. 4.6 hours for BMI $<25 \mathrm{~kg} / \mathrm{m}^{2}$ compared to 5.4 hours for BMI $\geq 40 \mathrm{~kg} / \mathrm{m}^{2}$ in multiparas). In addition, the adjusted interval-censored regression analysis suggests that these findings are independent of important covariates in the labor process including gestational age and induction. Furthermore, we also determined that the entry into active phase was delayed for multiparas as BMI increased. Differences in the second stage length did not persist in the adjusted analysis suggesting that other factors besides BMI (i.e. birth weight) play a role in the second stage of labor in nulliparas. This information highlights the concept that contemporary labor practices should take into account the changing profiles of obstetrical populations particularly increasing BMI. Allowing for a slower progression in labor for obese gravidas prior to intervening with a $\mathrm{CD}$ has the important potential of decreasing the number of $\mathrm{CD}$ performed for labor abnormalities. Further, changing labor practices in the obese gravida may impact additional perinatal outcomes such as decreasing infectious and other operative morbidities.

Other investigations report similar findings with respect to labor progression and maternal weight. In a smaller prospective study of nulliparas at term where BMI categories were determined by the prepregnancy weight using the same statistical methods (interval censored regression), the authors reported that obese and overweight gravidas were not only admitted earlier in labor, had more inductions, and required more oxytocin, but also had a longer median duration of labor in progressing from $4-10 \mathrm{~cm}$ compared to normal BMI gravidas 
$\left(7.9,7.5\right.$, and 6.2 hours respectively) ${ }^{18}$ This reflects a similar pattern described in the current study.

Two studies have compared induced labor progress by maternal weight. Term singleton gravidas were studied if their cervical exam on admission was $<2 \mathrm{~cm}$ and the maternal weight most proximate to delivery determined the weight categories, grouped into quartiles $\left(1^{\text {st }} 47-72 \mathrm{~kg}, 2^{\text {nd }} 72-85 \mathrm{~kg}, 3^{\text {rd }} 85-103 \mathrm{~kg}, 4^{\text {th }} 103-193 \mathrm{~kg}\right)$. Nulliparas in the $4^{\text {th }}$ quartile for weight had a lower mean cervical dilation rate $(0.63 \mathrm{~cm} / \mathrm{h})$ compared to the $1^{\text {st }}$ quartile $(1.0 \mathrm{~cm} / \mathrm{h}, \mathrm{P}=0.01)$, but these differences were not detected for multiparas. ${ }^{19}$ However, overall labor duration increased with each weight quartile for nulliparas $(12,13,14$, and 17 hours respectively, $\mathrm{P}<0.001)$ and multiparas $(7.4,8.1,8.4$, and 11 hours, $\mathrm{P}=0.01)$. Given that all patients had intrauterine pressure catheters and oxytocin protocols were standardized, the authors were able to conclude that decreased uterine responsiveness (measured in Montevideo units) or lower oxytocin doses did not account for slower labor progress or increased duration of labor as maternal weight increased. Furthermore, in a secondary analysis of a randomized comparator-controlled trial of dinoprostone and misoprostol, the median duration of active labor was 14.9 hours for a normal BMI, 16.0 hours for obese, and 19.3 hours for extreme obesity. ${ }^{25}$ Similarly, those in the lowest BMI category delivered 2 hours sooner than those in the overweight or obese category and 4 hours sooner than those in the BMI $>40 \mathrm{~kg} / \mathrm{m}^{2}$ category.

The labor curves in the current study reflect spontaneous as well as augmented and induced labor as these are common characteristics of contemporary labor management. We observed that nulliparas and multiparas with higher BMI's had less cervical dilation and greater induction rates. However, when we compared labor curves for spontaneous and induced labor by BMI category, the same result (slower labor progress with increasing BMI) was demonstrated (results not shown). As such, we concluded that labor inductions or augmentations alone did not account for the slower labor progress as BMI increased. We also included laboring gravidas whose delivery ultimately ended in a CD for the interval censored regression analysis as this is a common intervention in the labor process today as well. We noted that intrapartum CD increased with BMI, particularly in nulliparas (11.7\% for BMI $<25 \mathrm{~kg} / \mathrm{m}^{2}$ and $44.8 \%$ for BMI $\geq 40 \mathrm{~kg} / \mathrm{m}^{2}$ ). In addition, CD for labor abnormalities increased as BMI increased $(\mathrm{P}<0.0001)$. Since patients were not allowed to labor endlessly, subtracting out gravidas with a CD performed prior to reaching $10 \mathrm{~cm}$ from the labor curves (e.g. informative censoring) could have shortened the labor duration, changed labor curve patterns and impacted the comparisons among BMI categories to an unknown degree. However, as the rate of CD was directly related to BMI one would have expected this to actually decrease the differences among the labor curves by BMI categories, yet discrete labor curves were apparent for each BMI category.

Prior studies have speculated on the potential etiology for the differences in labor progression with increasing BMI. ${ }^{6-11}$ Increased fetal size or greater induction rates seem plausible but these factors can be controlled in the study design or analysis. It is possible that there is an underlying pharmacological mechanism such as decreased responsiveness to oxytocin or even an endocrinological alteration to explain these differences. Leptin is a protein hormone that plays a key role in regulating energy intake and expenditure, including appetite and metabolism. Longitudinal studies have demonstrated that maternal leptin levels not only increase with gestational age, but also with BMI. ${ }^{26-29}$ An in vitro study which evaluated leptin effects on human myometrium noted a physiologic inhibitory effect on contractility, suggesting that leptin may play a role in the dysfunctional labor process associated with maternal obesity. ${ }^{30}$ In fact, due to these effects on smooth muscle, another group of investigators has proposed leptin as a tocolytic in pregnancies complicated by preterm labor. ${ }^{31}$ 
Although most investigations that pertain to maternal weight use a prepregnancy weight to calculate BMI and determine weight categories, we opted to use admission BMI for our study since weight most proximate to delivery would have a greater impact on labor and delivery patterns. Although statistically significant, the results of the differences in the second stage duration for multiparas were of marginal clinical significance (i.e. 0.17 hours for BMI $<25 \mathrm{~kg} / \mathrm{m}^{2}$ compared to 0.12 hours for BMI $\geq 40 \mathrm{~kg} / \mathrm{m}^{2}$ ). This may at least in part be attributable to the high intrapartum $\mathrm{CD}$ for abnormal labor in obese gravidas. For example, had all gravidas been allowed to labor into the second stage, the difference would likely have been larger. Furthermore, the findings also support those of Buhimschi et al who found that second stage intrauterine pressure and duration in nulliparas and multiparas did not differ among BMI groups. ${ }^{32}$ There is also more variation in the duration of second stage in contemporary obstetrical practice such that intervention by operative delivery is considered in the absence of progress irrespective of labor duration. ${ }^{33}$ Without conclusive findings in the second stage, we would suggest the clinician focus primarily on the marked differences in the first stage of labor with increasing BMI. Finally, we acknowledge the lack of standard labor management across institutions, as well as the subjectivity of cervical exams as limitations in our work. The models for determining traverse time allow for nonsystematic error such as inter or intraobserver variability in the assessment of cervical dilation by increasing the standard errors of estimated parameters which can reduce the power to detect differences. However, the models do not account for systemic variability that might be affected by BMI (i.e. more difficult exams in obese patients) and we also recognize this as a limitation in our study.

We determined that as maternal BMI increases labor progresses more slowly and labor duration increases. Based on our data, the effect of BMI on labor progression is clearly more pronounced in nulliparas. We suggest that obstetric providers take this information into consideration before intervening with a $\mathrm{CD}$ for abnormal labor, especially in nulliparas in whom delivery route may have a major impact on future pregnancy outcomes. Similar to other studies that have suggested greater patience in the labor process, ${ }^{34,35}$ consideration should be given to extending the traditionally considered upper limits for duration of labor based upon maternal BMI.

\section{Acknowledgments}

This study was supported by the Intramural Research Program of the Eunice Kennedy Shriver National Institute of Child Health and Human Development, National Institutes of Health, through a contract (Contract No. HHSN267200603425C) and by Grant Number K12HD055892 from the NICHD and NIH Office of Research on Women's Health (ORWH).

Institutions involved in the Consortium include, in alphabetical order: Baystate Medical Center, Springfield, MA; Cedars-Sinai Medical Center Burnes Allen Research Center, Los Angeles, CA; Christiana Care Health System, Newark, DE; Georgetown University Hospital, MedStar Health, Washington, DC; Indiana University Clarian Health, Indianapolis, IN; Intermountain Healthcare and the University of Utah, Salt Lake City, Utah; Maimonides Medical Center, Brooklyn, NY; MetroHealth Medical Center, Case Western University, Cleveland, OH.; Summa Health System, Akron City Hospital, Akron, OH; The EMMES Corporation, Rockville MD (Data Coordinating Center); University of Illinois at Chicago, Chicago, IL; University of Miami, Miami, FL; and University of Texas Health Science Center at Houston, Houston, Texas.

\section{References}

1. Hamilton BE, Martin JA, Ventura SJ. Births: preliminary data for 2009. Nat Vital Stat Rep. 2001; 59(3)

2. Joseph KS, Young DC, Dodds L, et al. Changes in maternal characteristics and obstetric practice and recent increases in primary cesarean delivery. Obstet Gynecol. 2003; 102:791-800. [PubMed: 14551010] 
3. Macones GA. Clinical outcomes in VBAC attempts: what to say to patients? Am J Obstet Gynecol. 2008; 199:1-2. [PubMed: 18585519]

4. Flegal KM, Carroll MD, Ogden CL, Curtin LR. Prevalence and trends in obesity among US adults, 1999-2008. JAMA. 2010; 303:235-41. [PubMed: 20071471]

5. Kominiarek MA, VanVeldhuisen P, Hibbard J, et al. for the Consortium on Safe Labor. The maternal body mass index: a strong association with delivery route. Am J Obstet Gynecol. 2010; 203:264.e1-7. [PubMed: 20673867]

6. Barau G, Robillard P, Hulsey T, et al. Linear association between maternal pre-pregnancy body mass index and risk of caesarean section in term deliveries. BJOG. 2006; 113:1173-1177. [PubMed: 16972860]

7. Sheiner E, Levy A, Menes TS, Silverberg D, Katz M, Mazor M. Maternal obesity as an independent risk factor for caesarean delivery. Paediatr Perinat Epidemiol. 2004; 18:196-201. [PubMed: 15130159]

8. Young TK, Woodmansee B. Factors that are associated with cesarean delivery in a large private practice: The importance of prepregnancy body mass index and weight gain. Am J Obstet Gynecol. 2002; 187:312-320. [PubMed: 12193918]

9. Weiss JL, Malone FD, Emig D, et al. Obesity, obstetric complications and cesarean delivery rate - a population-based screening study. Am J Obstet Gynecol. 2004; 190:1091-1097. [PubMed: 15118648]

10. Cnattingius S, Bergstrom R, Lipworth L, Kramer MS. Prepreganncy weight and the risk of adverse pregnancy outcomes. N Engl J Med. 1998; 338:147-52. [PubMed: 9428815]

11. Zhang J, Bricker L, Wray S, Quenby S. Poor uterine contractility in obese women. BJOG. 2007; 114:343-348. [PubMed: 17261121]

12. Friedman EA. The graphic analysis of labor. Am J Obstet Gynecol. 1954; 68:1568-75. [PubMed: 13207246]

13. Friedman EA. Primigravid labor: a graphicostatistical analysis. Obstet Gynecol. 1955; 6:567-89. [PubMed: 13272981]

14. Zhang J, Troendle JF, Yancey MK. Reassessing the labor curve in nulliparous women. Am J Obstet Gynecol. 2002; 187:824-8. [PubMed: 12388957]

15. Rinehart BK, Terrone DA, Hudson C, Isler CM, Larmon JE, Perry KG. Lack of utility of standard labor curves in the prediction of progression during labor induction. Am J Obstet Gynecol. 2000; 182:1520-6. [PubMed: 10871474]

16. Impey L, Hobson J, O’Herlihy C. Graphic analysis of actively managed labor: Prospective computation of labor progress in 500 consecutive nulliparous women in spontaneous labor at term. Am J Obstet Gynecol. 2000; 183:438-43. [PubMed: 10942483]

17. Zhang J, Landy HJ, Branch DW, et al. for the Consortium on Safe Labor. Contemporary patterns of spontaneous labor with normal neonatal outcomes. Obstet Gynecol. 2010; 116(6):1281-7. [PubMed: 21099592]

18. Vahratian A, Zhang J, Troendle JF, Savitz DA, Siega-Riz AM. Maternal prepregnancy overweight and obesity and the pattern of labor progression in term nulliparous women. Obstet Gynecol. 2004; 104:943-51. [PubMed: 15516383]

19. Nuthalapaty FS, Rouse DJ, Owen J. The association of maternal weight with cesarean risk, labor duration, and cervical dilation rate during labor induction. Obstet Gynecol. 2004; 103:452-6. [PubMed: 14990405]

20. Zhang J, Troendle J, Reddy U, et al. for the Consortium on Safe Labor. Contemporary cesarean delivery practice in the United States. Am J Obstet Gynecol. 2010; 203:326.e1-10. [PubMed: 20708166]

21. World Health Organization. Obesity: preventing and managing a global epidemic. World Health Organization Technical Report. 2000; 894:i-xii. 1-253.

22. Crowder, KJ.; Hand, DJ. Analysis of repeated measures. New York (NY): Chapman and Hall; 1990.

23. Klein, JP.; Moeschberger, ML. Survival analysis: techniques for censored and truncated data. Berlin: Springer; 1997. 
24. Vahratian A, Troendle JF, Siega-Riz AM, Zhang J. Methodological challenges in studying labour progression. Paediatr Perinat Epidemiol. 2006; 20:72-8. [PubMed: 16420344]

25. Pevzner L, Powers BL, Rayburn WF, Rumney P, Wing DA. Effects of maternal obesity on duration and outcomes of prostaglandin cervical ripening and labor induction. Obstet Gynecol. 2009; 114:1315-21. [PubMed: 19935035]

26. Highman TJ, Friedman JE, Huston LP, Wong WW, Catalano PM. Longitudinal changes in maternal serum leptin concentrations, body composition and resting metabolic rate in pregnancy. Am J Obstet Gynecol. 1998; 178:1010-1015. [PubMed: 9609576]

27. Schubring C, Englaro P, Sieble T, et al. Longitudinal analysis of maternal serum leptin levels during pregnancy, at birth and up to six weeks after birth: relation to body mass index, skinfolds, sex steroids and umbilical cord blood leptin levels. Horm Res. 1998; 50:276-83. [PubMed: 9873196]

28. Yang M. Interrelationships of Maternal Serum Leptin, Body Mass Index and Gestational Age. J Chin Med Assoc. 2005; 68:452-457. [PubMed: 16265858]

29. Madan JC, Davis JM, Craig WY, Collins M, Allan W, Quinn R, Dammann O. Maternal obesity and markers of inflammation in pregnancy. Cytokine. 2009; 47:61-64. [PubMed: 19505831]

30. Moynihan AT, Hehir MP, Glavey SV, Smith TJ, Morrison JJ. Inhibitory effect of leptin on human uterine contractility in vitro. Am J Obstet Gynecol. 2006; 195:504-509. [PubMed: 16647683]

31. Wuntakal T, Hollingworth T. Leptin-a tocolytic agent for the future? Med Hypotheses. 2010; 74:81-82. [PubMed: 19692183]

32. Buhimschi CS, Buhimschi IA, Malinow AM, Weiner CP. Intrauterine Pressure During the Second Stage of Labor in Obese Women. Obstet Gynecol. 2004; 103:225-230. [PubMed: 14754688]

33. American College of Obstetricians and Gynecologists. Dystocia and augmentation of labor. ACOG Practice Bulletin No. 49. Obstet Gynecol. 2003; 102:1445-54. [PubMed: 14662243]

34. Rouse DJ, Owen J, Savage KG, Hauth JC. Active Phase Labor Arrest: Revisiting the 2 - Hour Minimum. Obstet Gynecol. 2001; 98:550-554. [PubMed: 11576566]

35. Rouse DW, Owen J, Hauth JC. Active-Phase Labor Arrest: Oxytocin Augmentation for at Least 4 Hours. Obstet Gynecol. 1999; 93:323-328. [PubMed: 10074971] 


\section{8,668 Deliveries from Consortium on Safe Labor assessed for eligibility}

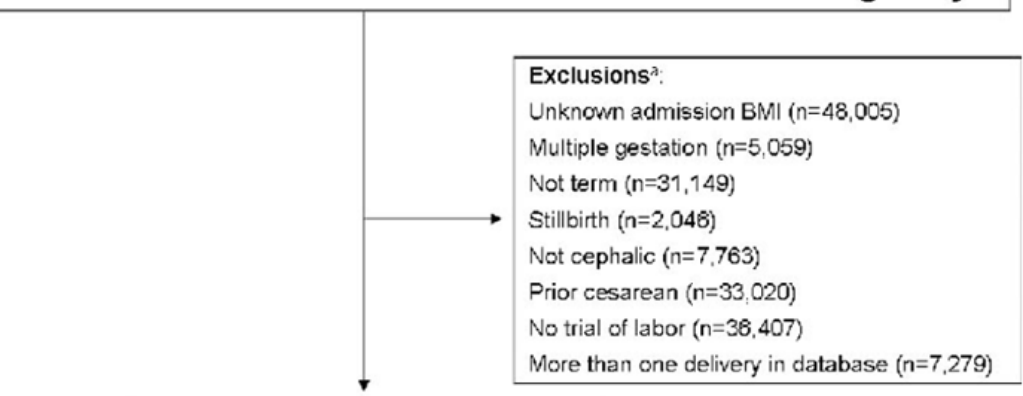

118,978 Eligible deliveries

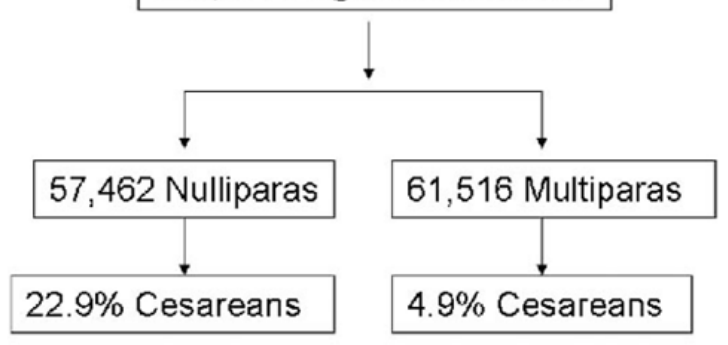

Figure 1.

Diagram of subject selection 
Labor Curves in Nulliparas by Body Mass Index Category

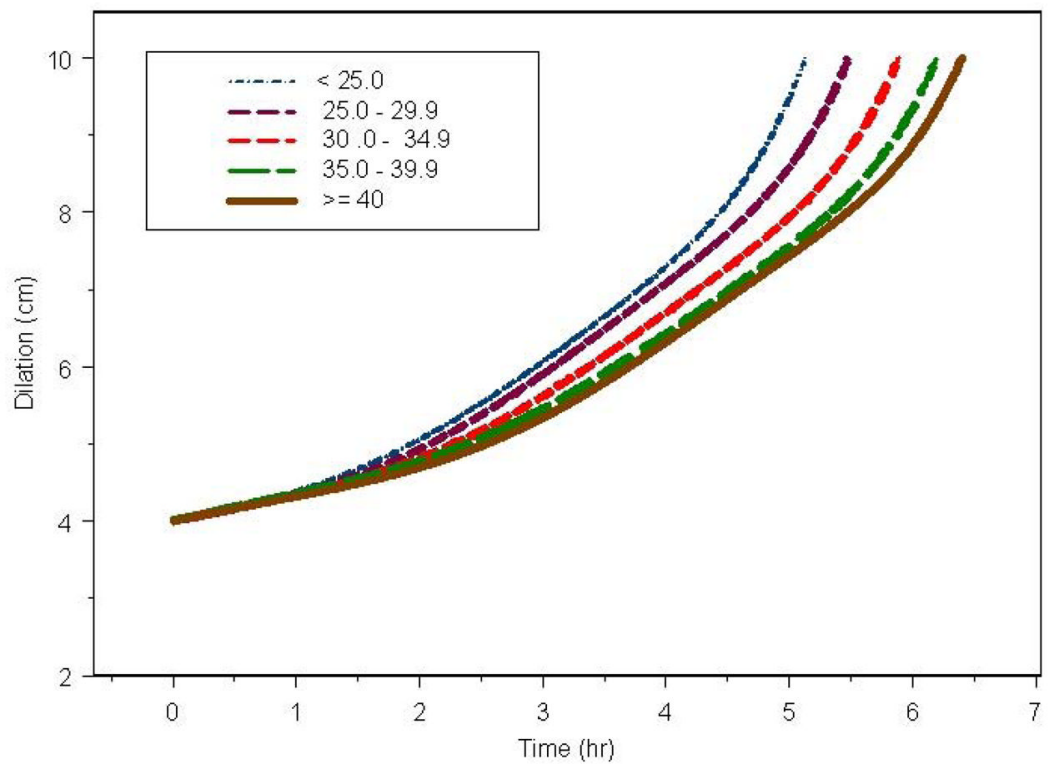

Figure 2.

Labor Curves in Nulliparas by Body Mass Index Category 
Labor Curves in Multiparas by Body Mass Index Category

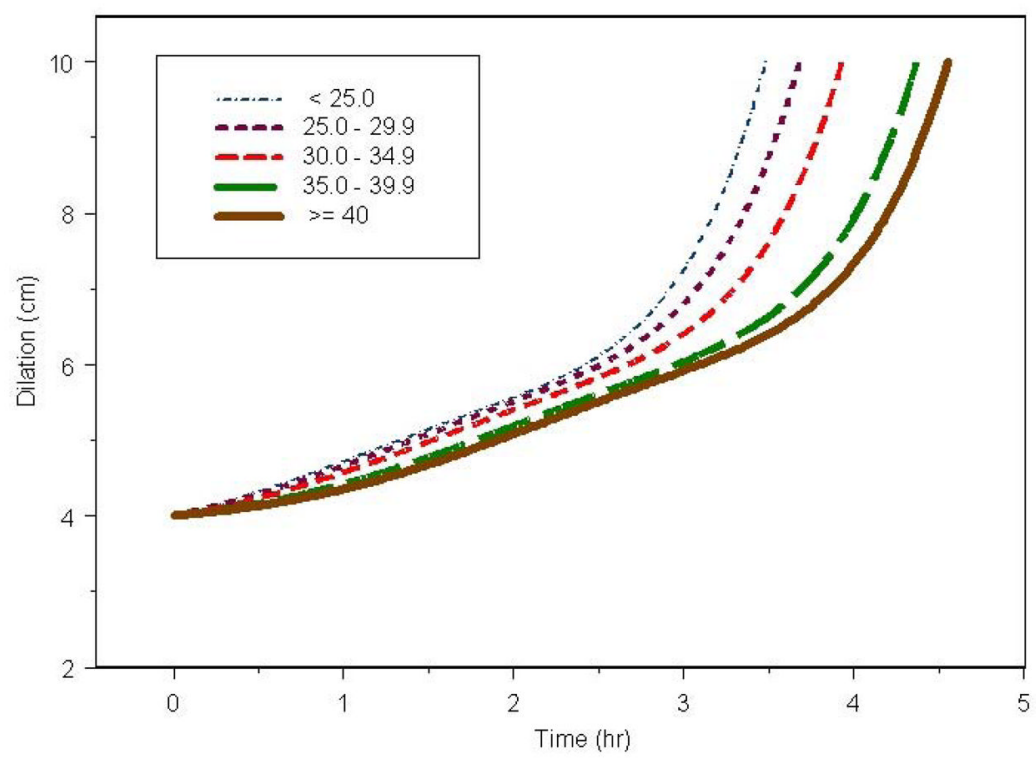

Figure 3 .

Labor Curves in Multiparas by Body Mass Index Category 


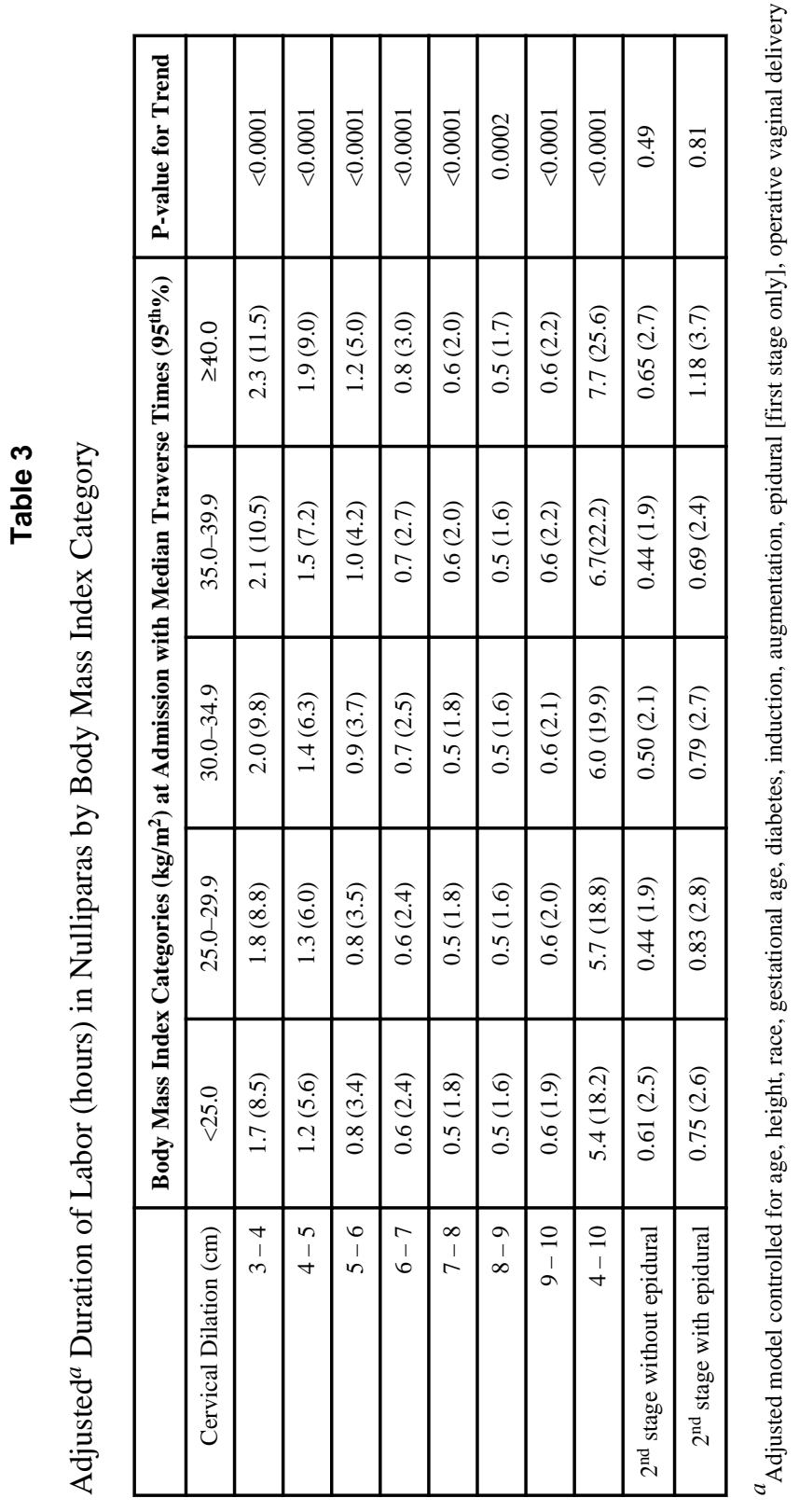

Am J Obstet Gynecol. Author manuscript; available in PMC 2012 September 1. 


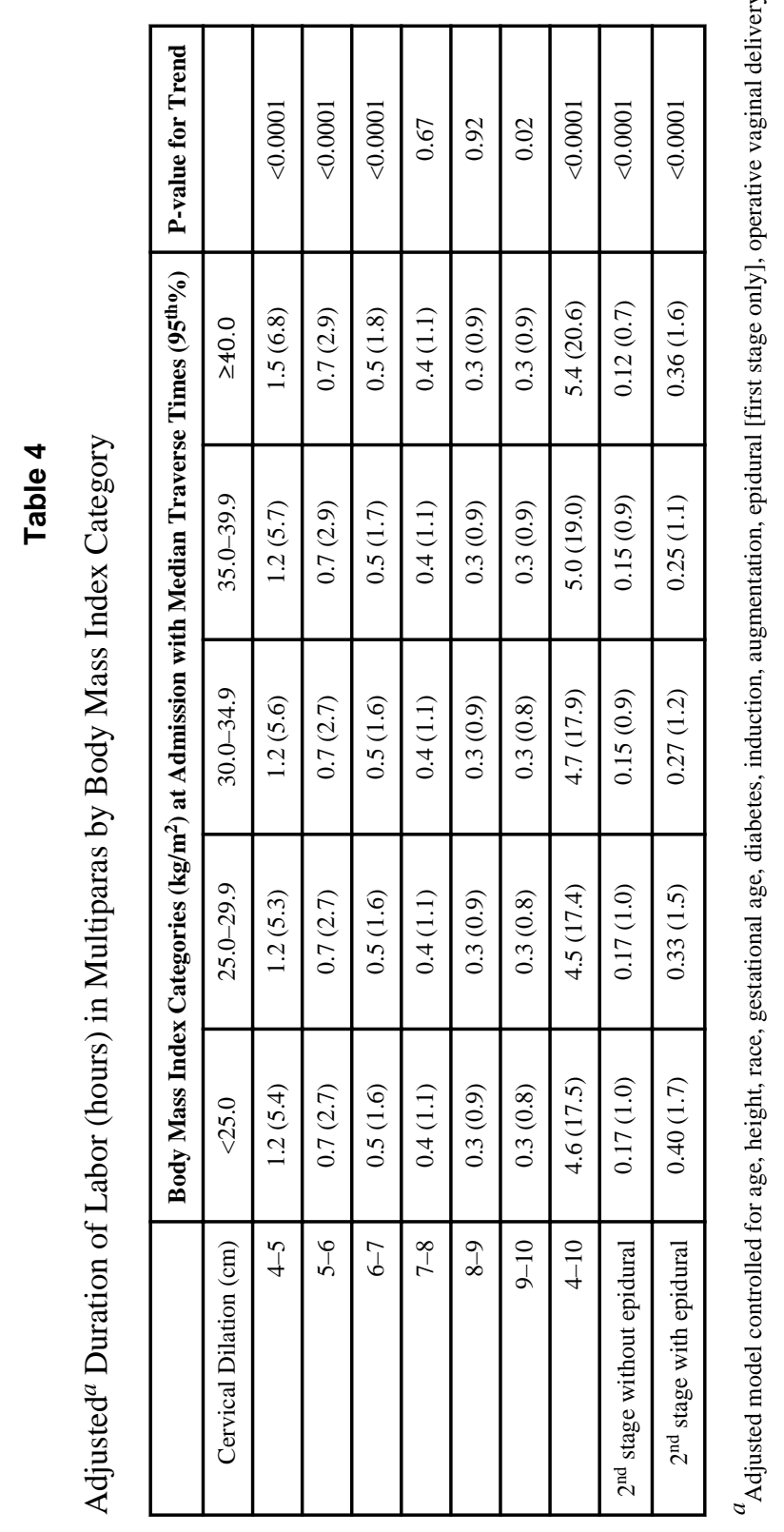

Am J Obstet Gynecol. Author manuscript; available in PMC 2012 September 1. 